\title{
An update on avian infectious coryza: its re- emerging trends on epidemiology, etiologic characterization, diagnostics, therapeutic and prophylactic advancements
}

\begin{abstract}
Avian Infectious coryza, a highly opportunistic respiratory tract infection caused by Avibacterium paragallinarum is now believed to be evolving as a re-emerging disease of poultry birds. Albeit adoption of strong precautionary/prophylactic measures i.e. vaccine/vaccination practice, the infection continues as complicated pattern of disease course worldwide that results in massive economic and production losses. India, being a major admirer of poultry products suffers tremendously with this insidious infectious insult every year, thus strives for some better optional measures to curtail this curse.

This review article blazons some significant development(s) that took place over the period of last decade with regards to its epidemiologic spectrum, characterization of its etiologic agent and important improvement(s)/advancement(s) in its diagnostic as well as prophylactic approach (es). Although, the major achievements to identify and restrict this disease has been carried out in early $80 \mathrm{~s}$ and $90 \mathrm{~s}$, however precarious nature of this organism has largely left scientific and farming community abstruse over its ambit on host specificity and geographic limitation(s). Following strong vaccinal/prophylactic measures, the causative organism(s) further acquired superlative advantages having by-passing host immune surveillance mechanisms acquired through existing vaccine components, besides violating constitutive immunity of host. The plausible reason behind such immunity exclusion is hitherto unknown, when it comes to host's response against pathogen. Resultantly, a detailed study to this effect is highly warranted to avoid further sinister in our poultry operation(s) due to Avibacterium paragallinarum infection. Most of the recent studies endeavoured to work on serovar $\mathrm{B}$ of Avibacterium paragallinarum organism which is quite prevalent at the moment at varied places across the globe. This warrants concerted/dedicated diagnostic techniques employing high end bio-molecular approaches for better comprehension of the disease, and to have a blue print with regard to adoption of newer therapeutic strategy towards containment of the infection for fruitful future.
\end{abstract}

Keywords: avian infectious coryza, Avibacterium paragallinarum, epidemiology, diagnostic, therapeutic and prophylactic approaches
Volume 2 Issue 3 - 2015

\section{Sidhartha Deshmukh, Harmanjit Singh Banga, Sandip Sodhi, Rajinder Singh Brar}

Department of Veterinary Pathology, College of Veterinary Science, India

\section{Correspondence: Sidhartha Deshmukh, Guru Angad Dev Veterinary and Animal Science University, Department of Veterinary Pathology, College of Veterinary Science, Gadvasu, Ludhiana-|4|004, Punjab, India, Tel 009| 947838 6269, Email sid0159@yahoo.com}

Received: March 13, 2015 | Published: June 02, 2015
Abbreviations: AIC, avian infectious coryza; TTC, 3, 3, 5-triphenyl-tetrazoil chlorhydrate; URT, upper respiratory tract; MV, membrane vesicles; PCR, polymerase chain reaction; HI, haemeagglutination-inhibition; rHagA, recombinant haemeaggltuniating antigen; HA, haemagglutinin

\section{Introduction}

Avian infectious coryza (AIC) is a serious respiratory tract infection of poultry birds caused by an opportunistic pathogen Avibacterium paragallinarum having an economic implication on poultry industry besides ornamental bird's population. ${ }^{1}$ The infection at times alone, as recorded in one of the outbreaks at California ${ }^{2}$ has been incriminated to cause heavy mortality reaching nearly to $50 \%$ and also drops in egg production by $75 \%$ to $15 \%$ within a little span of time. The disease usually runs as a complicated infective course in the Asian continent as well as in the Indian subcontinent. This is due to over intensive poultry operations and weather/seasonal conditions, in addition to interactions between several concomitant prevailing causative agents. However, the mortality counts less (i.e. nearly $10 \%$ ) than morbidity that usually reaches up to $100 \%$. Historically, the first clinical course of the disease was recognized in $1930^{3}$ and the infective agent was isolated first in the year 1931 by De Blieck. ${ }^{4}$

Off late, the etiologic agent of disease has gone through several taxonomic changes in its classification tree, ${ }^{5}$ since its actual evidence/ occurrence that qualify supposedly for the current scenario of vaccine failure(s) against the disease. Through this article, the author(s) intend to reflect some important information(s)/issue(s) for the integrated comprehension on the disease's epidemiologic status with special reference to Asian poultry operation(s) wherever deemed possible, its etiologic characterization and latest knowhow on its diagnostic and prophylactic advancement(s) besides few suggestions to improve the mucosal vaccination/prophylactic practices. 


\section{General information about Avian Infectious Coryza (AIC) and its etiologic organism}

Avian infectious coryza (AIC) is caused by Avibacterium paragallinarum, a well differentiated gram negative bacterium potentially pathogenic for poultry. In agar plate, the bacteria exhibit pleomorphic rod or coco-bacilli morphology with a tendency to form filament like arrangement with short chains, while in broth, it appears like a faded objects. Ordinarily, the size of bacterium ranges from 1 to $3 \mu \mathrm{m}$ in length and from 0.4 to $0.8 \mu \mathrm{m}$ in width. In most of the cases, the organisms are grown under micro aerobic or anaerobic conditions with increased levels of $\mathrm{CO} 2(5-10 \%)$. This organism can be traditionally grown in candle jar method or by incubating in $7-10 \%$ bovine/sheep defibrinated blood agar plate for $16-24 \mathrm{hrs}$ at $37^{\circ} \mathrm{C}$. It is believed that this organism can be grown well in haemolysed blood when compared with non haemolysed blood probably due to high availability of NAD through lytic erythrocyte. Interestingly, horse blood is considered as superior ingredients for the growth this fastidious organism.

Biochemically, the organism reduce nitrates to nitrites, causes fermentation of glucose without production of gas, negative oxidase activity and shows absence of catalase activity ${ }^{6,7}$ besides negative indol production, urea/gelatine hydrolysis, that essentially defines its features.

Vargas \& Terzolo ${ }^{8}$ indicated non- utilization of 3, 3, 5-triphenyltetrazoil chlorhydrate (TTC) by Avibacterium paragallinarum in order to produce formazan, has exclusively helps in identification of this bacterium from other gram negative bacteria. ${ }^{8}$ The disease has been characterized as a disease of upper respiratory tract that affects growing layer birds; (aged 8-12weeks) with its increasing ability to affect even very young and tender aged broiler chicks i.e. between 3 to 6 week(s) of age. This infection has been characterized in oriental countries as an insidiously progressing disease with complicated infectious course than as uncomplicated disease seen in the western countries. At initial stage of infection, the clinical symptom runs as sero-mucus discharge(s) mainly from nostrils and eyes, lately transforming into caseous flake like exudative deposits in the subcutaneous tissue, around the para- nostrils area as well as eyes, consequently resulting in sticky closures of eyes of birds (personal communication). Birds died with chronic course at most of time, exhibit similar flaky material as big creamish white organized mass or as white chunks of exudative material either unilaterally or bilaterally at infra-orbital/supra-orbital sinuses and is referred to as "swollen head syndrome". Besides, primarily involving upper respiratory tract (URT), the infection also transcend down to trachea, air sacs as well as cause pneumonia in lungs in very extreme cases. In older and egg laying chicken, the organism predominantly affect(s) the reproductive organs viz; ovary and salpinx and are responsible for poor egg quality and decreased egg production. In meat type birds, due to inanition, the feed conversion efficiency drastically declines, that mainly results in poor flesh development and extreme culling at tender age. In some of the rare clinical outcomes, the concomitant infection with opportunistic pathogens like Mycoplasma gallisepticum or other septicaemia causing bacteria eventually lead to arthritis and speticemic lesion.

It is now believed that the capsule of the Avibacterium paragallinarum plays a paramount role in the process of virulencity and colonization of bacteria within the ciliated epithelial cells of host's nasal mucosa. ${ }^{9,10}$ Apart from it, the haemagglutinin antigen of the organism has also been thought of to hold an important role in pathogenicity ${ }^{11}$ of bacteria besides, also acting as an immune sensitizing agent for the host.

Probably, this is one of the few organism(s) inflicting poultry against whom the early effort to undertake vaccination was carried out. To date back to 1960 s, egg propagated infectious coryza vaccine was first introduced to curb the menace of this infection. ${ }^{12}$ Later on, several other methods on preparation of infectious coryza vaccines were documented. Intriguingly, the distinctively and vastly different nature of this organism has largely eluded the effect of vaccination at many places across the globe. In brief, the etiologic agent in their earlier period of recognization was identified as Haemophillus gallinarum thatrequires $\mathrm{X}$ and $\mathrm{V}$ factor (NAD) for their in vitro growth. However, over a period of time, changes in growth requirement of the bacteria were realized that resulted in the re-naming of the bacteria as Haemophillus paragallinarum thatrequires only V factor (NAD) for growth. Later on, nearing to early 90 s, an evolution of further new kind to the existing type of Haemophillus paragallinarum was understood, that was NAD independent requiring no $\mathrm{V}$ factors for their growth. This continual process of periodic evolutionary changes in organism is apparently thought to be due to the vaccine pressure/adaption. This however, didn't enable the altered/transformed organism to acquire high virulencity. ${ }^{13}$ This has been further verified by an experimental manipulation of naturally recovered NAD dependent isolates from an outbreak, eventually transfected with plasmid from NAD independent isolates that resulted in reduced virulencity of the transformed strain. ${ }^{14}$

Earlier most of the commercial vaccine(s) against the disease were single serovar based, specific to the needs of localized/regional poultry operations. These were either completely protective against homologous serovar(s) or less partially protective against heterologus serovar(s). The reduced efficacy of such vaccines over a period of time could be attributed to the evolutionary changes in the bacterium and has largely mystified the poultry scientist and poultry industry to its new epidemiologic spectrum and genotypic adaptations.

So from this point onwards, our next emphasis would aim towards the current information achieved for Avibacterium paragallinarum as well as the disease condition seen through a process of thoughtful screening of certain endemic areas, that were afflicted heavily besides, broaching for various technological developments accomplished for its diagnosis and prophylactic measures advocated over period of recent years.

\section{Emerging epidemiologic spectrum of Avibacterium pa- ragallinarum infection}

Although, the infection follows a specific and restrictive pattern of disease occurrence confined to certain geo-climatic conditions, apart from the support by other interactive respiratory tract pathogens, the organism Avibacterium paragallinarum inconspicuously appeared to be panoramically effective in causing disease where environmental conditions are actually humid and hot with rain fed milieu (Personal communication). This can be scientifically corroborated to various, recent evidences of work on vaccinology against the disease, that originated either from Tropic of Cancer at Northern hemisphere or Tropic of Capricorn at Southern hemisphere that confirms organism's affinity to grow at arid to semi arid conditions.

Over a period of recent times, the organism gained superlative advantage on its evolutionary growth and acquired different protein and lipid profiles on its outer membrane surface to mask the vaccine 
onslaught. The current vaccines available against the prevalent serovars are no more protective against emerging serovars and have put several states and Nations on high risk to this re-emerging trend of infection outbreak(s) in the poultry operation(s). The recent outbreaks in Thailand, ${ }^{15}$ the work on isolates from Ecuador, Argentina, Zimbabwe along with its subsequent inclusion to commercial vaccines, ${ }^{16}$ besides, latest switch over of its host's range specificity, ${ }^{1}$ exclusively suggests organism's paradigm shift in its virulencity and pathogenicity pattern, based on current global geological variations.

Surprisingly serovar B of the Avibacterium paragallinarum, which was never been considered for its serious outbreak potential, is now being realized as one of the important, insidious serovars replacing several provincial serovars responsible for the current outbreaks..$^{17,18}$ All these outbreaks were seen at times, when efforts to limit infectious coryza have been undertaken largely through adoption of chimerical vaccine containing multivariant serovars. Similarly, the earlier instances, where Bragg et al., ${ }^{19}$ suggested serovars replacement as causal implication in disease outbreaks in many places across South African regions despite effective vaccination schedules and found serovar C3 as dominant serovar in wild form other than serovar A and serovar $\mathrm{C}$ that were by and large tagged in the vaccinated form. The spectrum of disease incidences has now increased from western end to eastern end of the globe. The perusal of literature(s) on disease occurrence at certain South East Asian poultry operations reflects the impression that disease occurrence due to serovar B assumed alarming concerns and are now being controlled through its inclusion in locally made vaccine(s)..$^{15,18,20}$ In India, the presence of serovar B of organism could not be ruled out due to its close proximity to some of the prominent poultry producing nations like Thailand, Bangladesh and others, apart from wide prevalence of serovar A and C, however no confirmed authenticated report on its occurrence till to date are available.

\section{Topical updates on Avibacterium paragallinarum cha- racterization}

In order to contain the serious, outrageous nature of disease outcome due to Avibacterium paragallinarum infections, it become imperative to understand the nature of the organism for effectively devising suitable vaccines or implementation of newer vaccination strategy. The use of anti-microbials against several other diseases for a longer period of time had drawn flak from various intellectual quarters with respects to increased incidences of microbial resistance due to mutations that resulted in serious public health consequences. Such configurational mutations would not be a surprise for Avibacterium paragallinarum, whose tendency remained fluctuating ever since its recognition and resulted in several emergences of non cross reactive and highly variable serovars over a period of time. The work on Avibacterium paragallinarum characterization dates back to Page classification, 1962 that demonstrated three serovars A, B and C based on plate agglutination test. ${ }^{12}$ Subsequently Kume characterization schemes were introduced for more confirmatory recognization of isolates that was based on haemeagglutination-inhibition test (A1, A-2, A-3, A-4, B-1, C-1, C-2, C-3 and C-4). Sawata et al. ${ }^{21}$ also conducted characterization process to evaluate serologically different isoform of the organism. ${ }^{21}$

The knowledge on Kume characterization extended information about role of haemagglutinin antigen in serotyping, immunity development and pathogenicity of organism in host. ${ }^{22}$ In addition to this, the capsular structure of the organism also appeared to be potentiating factor for the causation of disease in birds. ${ }^{23}$ Outer membrane proteins of Avibacterium paragallinarum similar to other bacteria such as Pasteurella organism seems to be associated with iron regulation process that further facilitates pathogen's metabolic pathway to accentuate pathogenic activity in host's body. It is important to understand that the only recent and valuable information acquired with regards to organism's characterization is a discovery of new protein system named RTX toxins among Avibacterium paragallinarum's membrane vesicles (MVs), ${ }^{24}$ which gets released extracellularly during normal or stressed growth condition, and were found out to be contributing elements towards virulencity and damage to host tissues in a big jig saw of disease puzzle. This particular toxin system has also been regarded as one of the potential candidate for the future vaccine development as sera of positively infected chickens exhibited recognition of molecular mass bands to western blotting technique(s).

Considering host specific virulencity, organism can further be characterized and has been shown serologically classified based on restricted virulencity pattern by host's serum, especially of turkey and guinea fowl when compared to chickens. ${ }^{25}$ Any possible deviation/departure from this unique feature of host's specific serological restriction could enable us in identification to emergence of new pathotypes. The latest evaluation on various Indian isolates of Avibacterium paragallinarum confirmed NAD dependency and reduced requirement to oxygen demand for their growth, ${ }^{26}$ implies minimal technological intervention on disease management through vaccination practices done against the organism, thus organism maintained its pristine, basic nature in Indian conditions. Incidentally, within paradoxes of non cross reactivity among serovars, besides continual emergence of atypical Avibacterium paragallinarum organism at different provincial region across globe, a slightly variant, newly classified bacterium was identified in 1994 and was named as Ornithobacterium rhinotracheale that was responsible for many outbreaks similar in symptoms to the then classified Haemophillus paragallinarum organism. Moreover, this organism in particular had mystified many poultry scientist with possible emergence of new variant of NAD independent type of Haemophillus paragallinarum, until understood through systematic distinguishing features on carbohydrate fermentation pattern. ${ }^{27}$ The idea of bringing this point here is to avoid incorrect identification of organism based on certain clinical symptoms and few handfuls of biochemical features. Thus a wrong interpretation could warrant inadvertent adoption of therapeutic regimen, which may digress us from actual targeted diseases that is not, principally involved i.e. infectious coryza.

\section{Diagnostic approaches and new advancements made for Avibacterium paragallinarum detection}

In yester years, various ancillary tests viz; isolation of bacterium along with biochemical characterization used to be set procedures to confirm the presence of organism but with delayed intimation. The improvement in molecular diagnostics has largely curtailed the awaiting time for disease reporting in matter of hours to begin suitable therapeutic regimen in shortest possible time point. Apart from this, the cogent identification of the provincial sero/immuno vars to conclusive, comprehensive region specific vaccine development has immensely appreciated these molecular diagnostic approaches for its boon. Polymerase chain reaction (PCR) test, a molecular tool has now become largely indispensable to its (Avibacterium paragallinarum) 
identification with having advantages closely accurate to conventional techniques i.e. culture, with much rapidity that avoids concept of false negativity. ${ }^{28,29}$ Very recently, Sakamoto et al. ${ }^{30}$ introduced the concept of multiplex PCR-RFLP technique to effectively sort Avibacterium paragallinarum to a serotype/serovar level for its final confirmation, in which HMTp210, an outer membrane protein of organism was evaluated to its region based DNA sequence homology. ${ }^{30}$ Instead of using ERIC-PCR techniques, to identify each serovars of Avibacterium paragallinarum, as adopted earlier by Soriano et al., ${ }^{31}$ that putatively created confusion in identification of several gel based patterns on nitrocellulose membrane for each serovar, the multiplex PCR-RFLP technique used by Sakamoto and his co-worker, helped them in identification of a distinct fraction in region 2 of the three regions of DNA sequences between serovar A, B and C and formally demonstrated a distinction of nearly $50 \%$ between each serovar and was highly innate to serovar specific. ${ }^{31}$ Even they also unveiled distinction to a level of $0.2 \%$ amongst serovars, thus improved the diagnostic confirmation to next level than as developed by Chen and his co-workers that was based on HP-2 PCR techniques. The latest work emanated from India by Anjaneya et al., ${ }^{32}$ includes PCR based RFLP technique and phylogeny tree analysis to ascertain the serotype prevailing in various northern regions of India and found a close conformity with known Australian serovar A and serovar C, thus attributing to the presence of only these two stated serovars rampant in India. ${ }^{32}$

Apart from the organism's based identification and confirmation techniques, host's based diagnostic options are in use since its (organism's) emergence as well as from the beginning of development of vaccines against the disease. Host's based diagnostics include; detection of antigen/serovar specific antibody in circulation and for this Haemeagglutination- Inhibition (HI) test is an important test and is in wide use. There are various types of $\mathrm{HI}$ tests available and several infrequent doubts were misted up over its sound conclusion to its effective correlation between infection/titre to protection level ${ }^{33,34}$ and remained still inconclusive..$^{35}$ However in recent outbreak history associated with serovar B at Thailand, Chukiatsiri et al., ${ }^{15}$ employed strategically $\mathrm{HI}$ test which confirmed the presence of serovar B infection, besides utilization of HPG-2 based PCR techniques for confirmatory diagnosis to infectious coryza. ${ }^{15}$

Monoclonal antibody based ELISA techniques were also employed previously ${ }^{36}$ to detect the evidence of Avibacterium paragallinarum infection in host. It was reported to have good specificity and acceptable level of sensitivity. However, owing to organism's elusive and changing potential pattern pertaining to its surface protein(s) amongst various sero/immuno vars with time and geo-climatic variations, supposedly denigrates ELISA's suitability at wide spread level. ${ }^{37-39}$ We believe, a great deal of effort is required to encompass series of monoclonal antibodies against each repositories of serovars/immuno vars of the organism's to have conglomerate into a single kit to evaluate the presence of particular antigenic types in the host system, so as to make the diagnostic test more robust and sensitive for correlating titre with infection level/protection.

\section{Newer knowledge on therapeutic and prophylactic measures against Avibacterium paragallinarum}

Despite having tremendous success to curtail the disease through means of vaccination practices, the current commercially available vaccines at many places are not fully competent to confer protection against the disease. So in such cases, disease assumed fulminating potential and resulted in gradual and massive outbreaks. To this situation, antibiogram susceptibility becomes a second in fiddle practice to counteract such consequent losses to vaccine failures. The perusal of literature(s) revealed variable results for antimicrobial sensitivity and fluctuating pattern from regional based pathotypes of this organism. Blackall et al. ${ }^{40}$ for the first time characterized several isolates of Australian origin into five antimicrobial drug resistance patterns and similar phenomenon was endorsed later by Fernandez et al. ${ }^{41}$ on Mexican isolates.

In wider perspective, the majority of the latest findings/observations on antimicrobial sensitivity studies have been particularly emanated from Asian countries ${ }^{42-44}$ with several from India. ${ }^{1,45-47}$ These pathogens were found to be sensitive to penicillin and few new generation penicillin groups of compounds that include, amoxicillin, ampicilin etc. Macrolide antibiotics such as erythromycin, third generation Fluro-quninolone antibiotics like enrofloxacin were also found to be partially effective against some isolates. Most of the isolates have shown resistance mainly against sulphonamides and partly to amino-glycosides (more specifically to streptomycin) and tetracycline group of compounds with rare sensitivity to gentamycin and oxy-tetracycline compound, respectively in many cases. As stated before, the advent of vaccine against Asian isolates of Avibacterium paragallinarum especially at South East Asian countries didn't assumes to its good faith ever and veterinarians continued to advocate antibiotics as a therapeutic regimen against the disease.

For prophylactic measures, western and developed countries afforded development of vaccine against the disease much earlier with inclusion of the local strains; however experiences of several vaccine failures owing to emergence of new bio-variants were also evident. The best part of their disease control programme was keen recognization of ill effects of antibiotics to their public health domain and immediately abstained from antibiotic usage. Despite their failure in controlling the disease outbreak(s), they continued to strive for research on new vaccines as well as newer strategy to vaccination procedure(s) and vaccine development. To this direction, many efforts were undertaken and one such important development was molecular designing and synthesis of recombinant haemeaggltuniating antigen (rHagA) that unfortunately yielded poor immunoprotective results in host. ${ }^{48}$ Previously, in past decades, where serotype B was challenging pathotypes, some researchers actuated work on immunoprotection against all the prevalent bio-vars by developing single tetravalent vaccine and achieved some degree of protection and success. ${ }^{15,16}$ It is further important to note that during course of such vaccine development and in other subsequent studies particularly, it was observed that single shot immunization of tetravalent vaccine does not yield appreciable immune response, but evoked good protection in host in terms of survivality/life expectancy and clinical sign development, while double shot immunization at 8 weeks apart yielded both relevant immune response and protection against the diseases, therefore questioned definitive predictor for vaccine efficacy in future. ${ }^{49}$

Having such inconclusive insight on protective efficacy of several developed vaccines, some researcher considered certain factors as a hindrance to evaluate the vaccine efficacy and they are as infection dosage, individual differences of the host's (chicken) and choice of infection model, besides non-standardisation of pathogenicity effects on host which is otherwise markedly complicated..$^{50}$ Their studies also 
suggested that natural way of disease transmission phenomenon or simulated manner of disease transmission during experimentation could reflect valuable information on natural process of spreading, sticking and proliferation of germs among hosts (birds) and may evaluate the definite understanding to pathopoietic mechanism of Avibacterium paragallinarum to suggest variance seen in vaccine efficacy study.

In a more recent work from China, ${ }^{51}$ who had elaborated work on oil based bacterins in terms of its dosing, period of protection and vaccine storage condition, put forth a new findings with respect to dosing regimen that had taken account of over-vaccinal dosing as well as closely placed normal dosing pattern as stimulating undertaking for having an appreciable level of immune protection in host without any adverse reaction, particularly delivered long term protection up to 38 months post, last vaccination that went well in to the laying life of the flock.

\section{Vaccines and vaccination against the disease}

Both killed adjuvant associated and live vaccines are available against the disease. As mentioned elsewhere, that no convincing, specific protective antigen against multiple serovars of this organism have been identified so far, an issue of failure of cross protective mechanism still exists with this disease. Previously workers across globe have tried killed vaccines based on egg yolk culture or tissue culture grown antigens and found certain degree of cross protection when compared with killed vaccines based on broth grown antigen. Interestingly, the most suitable protective antigen was found out to be Haemagglutinin (HA) of the polysaccharides capsule of this bacterium and was putatively considered as immuno- stimulating. ${ }^{52}$ In another study, people evaluated appreciable, good homologous protection following the usage of broth based antigens. ${ }^{53,54}$ The inactivating agent also seems to be affecting the efficacy of the killed vaccine and was observed at several trials and apparently shown thimerosal as a best agent over formalin. When considered adjuvants, Aluminium hydroxide had shown better efficacy and less adverse reaction to the site of injections over mineral oil based adjuvants. Usually, vaccination with two doses of aluminium hydroxide killed infectious coryza vaccine at three weeks apart extends a long term immune protection, which lasts for around 30-40weeks after vaccination.

Vaccination with live vaccines containing avirulent Avibacterium paragallinarum insinuate very closelyto natural exposure, where it is believed that the cross serovar protection would be higher as compared to killed vaccines, apart from easy, natural route of administration. The work by Blackall and his colleagues ${ }^{55}$ proved similar observation, having better cross protection against different virulent serovars following utilization of live attenuated strains of Avibacterium paragallinarum. Similarly chemically mutated strains of bacteria were also created and significant level of protection was noted on experimental trials. ${ }^{55}$ Despite of this development, killed vaccines are predominantly in use globally, probably because of fear about genetic transmutation of live strains of bacterium in to more pathogenic serovars. In young chicks, the vaccination against this disease is mainly carried out at the age of 6-8weeks of age and also before the age of egg laying.

\section{Conclusion}

Finally, we can further conclude based on above accretion of knowledge on prophylactic measures against the diseases with regards to vaccine development, that significant understanding on specific immunological mechanism elicited during natural development of disease is markedly lacking which failed to count on to demonstrate several correlates of immune response associated with protection/ survivality of host or enhanced diseases process/rate limiting steps. We believe that mucosal stimulation of innate immunity to this precarious bacterium by formulating a cock tail vaccine containing important immunogenic contents related to the absolute morphological structure of organism in one go would penetrate the discrepancies of immune response mechanism and unravel the reason for its suppression during enhanced disease process and may avoid tremendous systemic haulage against infective process.

Our group to this aspect contemplate in undertaking a research on deciphering the immuno-pathological intricacies involved during disease process to redefine the new vaccine development, formulation and strategies to combat with this economically depressive disease in our poultry operations.

\section{Acknowledgements}

None.

\section{Conflict of interest}

Author declares that there is no conflict of interest.

\section{References}

1. Priya PM, Vamshi Krishna S, Dinesh kumar V, et al. Isolation and characterization of Avibacterium paragallinarum from ornamental birds in Thrissur, Kerala. International Journal of Life Sciences. 2012;1(3):87-88.

2. Bland MP, Brickford AA, Charlton BR, et al. Case report: a severe infectious coryza infection in a multi-age layer complex in central California. 51st Western Poultry Diseases Conference/XXVII Convencion annual ANECA. Peurto Vallajarta, Mexico; 2002;56-57.

3. Blackall PJ, Matsumoto M, Yamamoto R. Infectious coryza. In: Calnek BW, editor. Diseases of Poultry. 10th ed. Ames: Iowa State University Press; 1997. p. 179-190.

4. De Blieck L. A haemoglobinophilic bacterium as the cause of contagious catarrh of the fowl. Veterinary Journal. 1932;88:9-13.

5. Blackall PJ, Christensen H, Beckenham T, et al. Reclassification of Pasteurella gallinarum (Haemophilus) paragallinarum, Pasteurella avium and Pasteurella volantium as Avibacterium gallinarum gen.nov, comb. nov., Avibacterium paragallinarum comb. nov. Avibacterium avium comb. nov and Avibacterium volantium comb. nov. Int J Syst Evol Microbiol. 2005;55(Pt 1):353-362.

6. Tongaonkar S, Deshmukh S, Blackall PJ. Characterization of Indian isolates of Haemophilus paragallinarum. Proceedings of the 51st western Poultry Disease Conference, Peurto Vallajarta, Mexico; 2002. $58 \mathrm{p}$.

7. Kaur J, Sharma NS, Gupta K, et al. Epidemiological studies on infectious coryza in chickens in northern India. Indian Journal of Animal Science. 2004;74(2):462-465.

8. Vargas ES, Terzolo HR. Haemophillus paragallinarum: Etiology of infectious coryza. Veterinarni México. 2004;35(3):245-259.

9. Ueda S, Nagasawa Y, Suzuki T, et al. Adhesion of Haemophilus paragallinarum to cultured chicken cells. Microbiology and Immunology. 1982;26(11):1007-1016. 
10. Nakamura K, Hosoe T, Shirai J, et al. Lesions and immunoperoxidase localisation of Haemophilus paragallinarum in chickens with infectious coryza. Veterinary Record. 1993;132:557-558.

11. Yamaguchi T, Kobayashi M, Masaki S, et al. Isolation and characterization of a Haemophilus paragallinarum mutant that lacks a heameagglutinating antigen. Avian Dis. 1993;37(4):970-976.

12. Page LA. Haemophilus infections in chickens. 1. Characterization of 12 Haemophilus isolates recovered from diseased chickens. Am J Vet Res. 1962;23:85-95.

13. Bragg RR. Effects of differences in virulence of different serovars of Haemophilus paragallinarum on perceived vaccine efficacy. Onderstepoort J Vet Res. 2005;72(1):1-6.

14. Taole M, Albertyn J, Van Heerden E, et al. Virulence of South African isolates of Haemophilus paragallinarum. Part 3: experimentally produced NAD-in dependant isolate. Onderstepoort $J$ Vet Res. 2002;69(3):189-196.

15. Chukiatsiri K, Chotinun S, Chansiripornchai N. An outbreak of Avibacterium paragllainarumserovar B in a Thai Layer farm. Thai Journal of Veterinary Medicine. 2010;40:441-444.

16. Jacobs A, van den Berg K, Malo A. Efficacy of a new tetravalent coryza vaccine against emerging variant type B strains. Avian Pathology. 2003;32(3):265-269.

17. Kume K, Sawata A, Nakase Y. Relationship between protective activity and antigen structure of Haemophilus paragallinarum serotypes 1 and 2. Am J Vet Res. 1980;41(1):97-100.

18. Zhang PJ, Miao M, Sun H, et al. Infectious coryza due to Haemophillus paragallinarum serovar B in China. Aust Vet J. 2003;81(1-2):96-97.

19. Bragg RR, Coetzee L, Verschoor JA. Changes in the incidence of the different serovars of Haemophillus paragallinarum in South Africa: A possible explanation for vaccine failure. Onderstepoort $J$ Vet Res. 1996;62:261-270.

20. Poernomo S, Sutarma, Rafiee M, et al. Characterization of isolates of Haemophillus paragallinarum from Indonesia. Aust Vet J. 2000;78(11):756-762.

21. Sawata A, Kume K, Nakase Y. Biologic and serologic relationships between Page's and Sawata's serotypes of Haemophillus paragallinarum. Am J Vet Res. 1980;40(11):1901-1904.

22. Blackall PJ, Matsumoto M. Infectious coryza. In: Saif YM, editor Diseases of Poultry. 11th ed. Ames: Iowa State University Press; 2003. p. 691-703.

23. Sawata A, Kume K. Relationship between virulence and morphological or serological properties of variants dissociated from serotype 1 Haemophillus paragallinarum strains. J Clin Microbiol. 1983;18(1):49-55.

24. Ramón Rocha MO, García-González O, Pérez-Méndez A, et al. Membrane vesicles released by Avibacterium paragallinarum contains putative virulence factors. FEMS Microbiol Lett. 2006;257(1):63-68.

25. Byarugaba DK, Minga UM, Gwakisa PS, et al. Virulence characterization of Avibacterium paragllainarum isolates from Uganda. Avian Pathol. 2007;36(1):35-42.

26. Kumar A, Rawat M, Verma R. Studies on absolute requirement of NAD and reduced oxygen tension for growth of field isolates of Avibacterium paragallinarum of poultry origin. Indian Journal of Poultry Science. 2012;47(1):90-92.

27. Bragg RR, Greyling, JM, Beer TC, et al .Changes in the incidence of Haemophillus paragallinarum serovars in South Africa: A need for local vaccines. Budapest, Hungary: XI International Congress of the World Veterinary Poultry Association; 1997.
28. Chen X, Miflin JK, Zhanq P, et al. Development and application of DNA probes and PCR tests for Haemophillus paragallinarum. Avian Dis. 1996;40(2):398-407.

29. Chen X, Chen Q, Zhanq P, et al .Evaluation of a PCR test for the detection of Haemophillus paragallinarum in China. Avian Pathol. 1998;27(3):296-300

30. Sakamoto R, Kino Y, Sakaguchi M. Development of a Multiplex PCR and PCR-RFLP method for serotyping of Avibacterium paragallinarum. J Vet Med Sci. 2012;74(2):271-273.

31. Soriano VE, Tellez G, Hargis BM, et al. Typing of Haemophillus paragallinarum strains by using enterobacterial repetitive intergenic consensus - based polymerase chain reaction. Avian Dis 2004;48(4):890-895.

32. Anjaneya Singh SD, Dhama K, Wani MY, et al. Molecular characterization of Avibacterium paragallinarum isolated from poultry flocks of India. Asian Journal of Animal and Veterinary Advances. 2014;9(7):440-451

33. Sawata A, Kume K, Nakase Y. Haemagglutinin of Haemophillus paragallinarum serotype 2 organisms: occurrence and immunologic properties of haemagglutinin. Am J Vet Res. 1982;43(7):1311-1314

34. Yamaguchi T, Iritani Y, Hayashi Y. Serological response of chickens either vaccinated or artificially infected with Haemophillus paragallinarum. Avian Dis. 1988;32(2):308-312.

35. Blackall PJ. Infectious Coryza: Overview of the disease and new diagnostic options. Clin Microbiol Rev. 1999;12(4):627-632.

36. Zhang P, Blackall PJ, Yamaguchi T, et al .A monoclonal antibody blocking ELISA for the detection of serovar-specific antibodies to Haemophillus paragallinarum. Avian Dis. 1999;43(1):75-82.

37. Blackall PJ, Yamaguchi T, Iritani Y, et al. Evaluation of two monoclonal antibodies for serotyping Haemophillus paragallinarum. Avian Dis. 1990;34:861-864

38. Yamaguchi T, Kato K, Takigami S, et al. Serological classification of Japanese isolates of Haemophillus paragallinarum usingtwo serovarspecific monoclonal antibodies. Avian Dis. 1990;34(2):364-368.

39. Blackall PJ, Zheng YZ, Yamaguchi T, et al. Evaluation of a panel of monoclonal antibodies in the sub typing of Haemophillus paragallinarum. Avian Dis. 1991;35(4):955-959.

40. Blackall PJ. The avian haemophili. Clin Microbiol Rev 1989;2(3):220-277.

41. Fernandez RP, Garcia-Delgado GA, Ochoa P, et al. Characterization of Haemophillus paragallinarum isolates from Mexico. Avian Pathol. 2000;29(5):473-476.

42. Roshan Akter M, Rahman-Khan MS, Mostafizur Rahman M, et al Investigation on infectious coryza of layer chicken in Bangladesh with isolation, identification and antibiogram study. Scientific Journal of Veterinary Advances. 2013;2(6):83-89.

43. Noonkhokhetkong T, Chukiatsiri K, Sasipreeyajan J, et al. Determination of antimicrobial susceptibility, antimicrobial resistance, genes and in vitro testing of Anti-microbial susceptibility of Avibacterium paragallinarum. Thai Journal of Veterinary Medicine. 2013;43(4):525-531.

44. Akter S, Saha S, Khan KA, et al. Isolation and identification of Avibacterium paragallinarum from layer chickens in Gazipur, Bangladesh. Microbes and Health. 2014;3(1):9-11.

45. Rajurkar G, Roy A, Yadav MM. Antimicrobial sensitivity pattern of Haemophillus paragallinarum isolated from suspected cases of infectious coryza in poultry. Vet World. 2010;3(4):177-181 
46. Thenmozhi V, Malmarugan S. Isolation, identification and antibiogram pattern of Avibacterium paragallinarum from Japanese quails. Tamil Nadu Journal of Veterinary and Animal Sciences. 2013;9(4):253-258.

47. Durairajan R, Sharma M, Murugan MS. Detection of Avibacterium paragallinarumin commercial poultry and their antibiogram. Tamil Nadu Journal of Veterinary and Animal Sciences. 2013;9(5):332-337.

48. Hsu YM, Shieh HK, Chen WH, et al. Immunogenicity and haemeagglutination of recombinant Avibacterium paragallinarum Hag A. Vet Microbiol. 2007;122(3-4):280-289.

49. García A, Romo F, Ortiz AM, et al. The vaccination -challenge trial: the gold standard test to evaluate the protective efficacy of infectious coryza vaccines. Avian Pathol. 2008;37(2):183-186.

50. Zhao Q, Sun YN, Zhang XX, et al. Evaluation of two experimental infection models for Avibacterium paragallinarum. Vet Microbiol. 2010;141(1-2):68-72.
51. Gong Y, Zhang P, Wang H, et al. Safety and efficacy studies on trivalent inactivated vaccines against infectious coryza. Vet Immunol Immunopathol. 2013;158(1-2):3-7.

52. Iritani Y, Katagiri K, Arita H. Purification and properties of Haemophilus paragallinarum haemagglutinin. American Journal of Veterinary Research. 1980;41(12):2114-2118.

53. Matsumoto M, Yamamoto R. Protective quality of an aluminium hydroxide absorbed broth bacterins against infectious coryza. Am J Vet Res. 1975;36(4 Pt 2):579-582.

54. Davis RB, Rimler RB, Shotts Jr RB. Efficacy studies of Haemophillus gallinarum bacterin preparations. American Journal of Veterinary Research. 1976;37(2):219-222.

55. Blackall PJ, Rafiee M, Graydon RJ, et al. Towards a live infectious coryza vaccine. Proceedings of the XIIth World Veterinary Poultry Association Conference. 1993. 99p. 